University of Wollongong

Research Online

Faculty of Commerce - Papers (Archive)

Faculty of Business and Law

March 2005

\title{
A Cross-Country Analysis of High Employment Generating Industries
}

Abbas Valadkhani

University of Wollongong, abbas@uow.edu.au

Follow this and additional works at: https://ro.uow.edu.au/commpapers

Part of the Business Commons, and the Social and Behavioral Sciences Commons

\section{Recommended Citation}

Valadkhani, Abbas: A Cross-Country Analysis of High Employment Generating Industries 2005. https://ro.uow.edu.au/commpapers/388 


\title{
A Cross-Country Analysis of High Employment Generating Industries
}

\begin{abstract}
The objective of this paper is to identify high employment industries in Australia, Japan and the U.S using input-output (IO) analysis. It is found that (1) the high and low employment generating industries in 1980 and/or 1990 are almost the same as those in 1997. Thus on a relative basis, there is no evidence that high employment generating industries have changed since 1980; and (2) the high and low employment generating industries are very similar across these three countries. Four of the consistently high employment generating industries in these countries are Food, Beverage and Tobacco; Chemicals, Petroleum, Coal, Rubber \& Non-Metallic Minerals; Basic Metals/Fabricated Products; and Electricity, Gas and Water, with the first three industries being part of manufacturing.
\end{abstract}

Keywords

Input-output analysis, Employment, OECD.

Disciplines

Business | Social and Behavioral Sciences

Publication Details

This article was originally published as Valadkhani, A, A Cross-Country Analysis of High Employment Generating Industries, Applied Economics Letters, 12(14), 2005, 865-69. Copyright Taylor \& Francis. Original journal available here. 


\section{A Cross-Country Analysis of High Employment Generating Industries}

Abbas Valadkhani

School of Economics

University of Wollongong,

Wollongong NSW 2522

Email: abbas@uow.edu.au

Tel: 02-4221 4022

Fax: 02-4221 3725 


\title{
A Cross-Country Analysis of High Employment Generating Industries
}

\begin{abstract}
The objective of this paper is to identify high employment industries in Australia, Japan and the U.S using input-output (IO) analysis. It is found that (1) the high and low employment generating industries in 1980 and/or 1990 are almost the same as those in 1997. Thus on a relative basis, there is no evidence that high employment generating industries have changed since 1980; and (2) the high and low employment generating industries are very similar across these three countries. Four of the consistently high employment generating industries in these countries are Food, Beverage and Tobacco; Chemicals, Petroleum, Coal, Rubber \& Non-Metallic Minerals; Basic Metals/Fabricated Products; and Electricity, Gas and Water, with the first three industries being part of manufacturing.
\end{abstract}

JEL classification numbers: C67, D57, and J21.

Key words: Input-output analysis, Employment, OECD.

\section{INTRODUCTION}

Persistent unemployment and underemployment continue to pervade Australia and many other OECD countries. For example, Mitchell and Mosler (2002, p.243) argue that the Australian economy has not generated "enough jobs in the last 25 years to match the growth of the labour force". A rising level of underemployment and casualisation of the workforce are now considered as critical issues..

Against the background of these stylized facts, the major objective of this paper is to identify the leading employment generating sectors in three countries which have shown some common characteristics in this respect. Given the rising level of underemployment and the increasing number of discouraged workers, it is important to identify these sectors, particularly in times of high employment. In other words, if rising and persistent unemployment is deemed to be an important socioeconomic phenomenon, one of the solutions would be to stimulate economic activity in high employment generating industries. The rankings and empirical analysis undertaken in this study shed some light on the sectoral potential in relation to the creation of jobs in these three economies.

The rest of the paper proceeds as follows. Section II briefly discusses the theoretical framework of the paper. Section III describes the sources of the IO tables which have been utilised to identify high employment generating industries. Section IV enlists the high employment generating industries in Australia, Japan and the U.S and how they have changed through time from 1980 to 1997. Section V provides some concluding remarks.

\section{THE THEORETICAL FRAMEWORK}

Given the objective of this paper, as a starting point let us begin with the following relation:

$$
(\mathbf{I}-\mathbf{A}) \mathbf{x}=\mathbf{f}
$$


where $\mathbf{A}$ is the (n x n) matrix of current price, domestic input-output coefficients, based on the direct allocation of imports; $\mathbf{x}$ is the ( $\mathrm{n} \times 1$ ) column vector of sectoral gross outputs; and $\mathbf{f}$ is the ( $\mathrm{n} \times 1)$ column vector of the sectoral final demands.

Then the solution vector of sectoral gross outputs, $\mathbf{x}$, can be written as

$$
\mathbf{x}=(\mathbf{I}-\mathbf{A})^{-1} \mathbf{f}=\mathbf{G f}
$$

where $\mathbf{G}=(\mathbf{I}-\mathbf{A})^{-1}$ is the inverse of the Leontief matrix.

Employment multipliers are usually used to identify high employment generating industries. The employment multiplier for sector $\mathrm{j}$ is defined as:

$$
E_{j}^{m}=\sum_{i=1}^{n} \lambda_{i} g_{i j}
$$

where $\mathrm{g}_{\mathrm{ij}}$ is the $\mathrm{ij}^{\text {th }}$ element of the Leontief inverse matrix, and $\lambda_{i}(i=1,2, \ldots n)$ denotes the direct labour coefficient per unit of gross output $i$.

An employment multiplier can be interpreted as the impact on employment if final demand in sector $j$ increases by one unit (e.g. one million US dollars, one billion Japanese Yen or a million Australian dollars). This measure is not unit free and if meaningful time series or cross-country comparisons are to be made, one needs to find a unit free index because the IO tables are expressed in current prices and different countries have different currencies. ${ }^{1}$ It should also be noted that the linkage and multiplier approaches, which are widely used in the literature, could mislead decisionmakers about the identification of the key sectors because the sectoral ranking based on employment linkages may identify relatively small industries as very important, or large-sized sectors as unimportant (Mattas and Shrestha, 1991).

Therefore, we use the Type I ratio which overcomes the problem of the units of measurement. The type I employment multiplier for sector $j$ is defined as follows:

$$
T_{\mathrm{j}}^{\mathrm{E}}=\sum_{i=1}^{n}\left(\lambda_{i} g_{i j}\right) / \lambda_{j}
$$

This means that for each additional person directly employed in sector $j$, a further $T_{j}^{E}$ are employed in the economy due to the multiplier and flow-on effects of sector $j$. For a detailed, technical discussion of this issue see Diamond (1975) and West (1993). This measure is independent of units of measurement and thus can be compared across countries and over time. ${ }^{2}$ Employment multipliers reveal the overall stimulus to employment from backward linkages arising from the expansion of a particular sector, but not the sectors that experience the increase in employment.

\section{THE DATA}

Consistent IO data for the three countries based on direct and indirect allocations and constant and current prices are available from the OECD under the ISIC rev2 classification from 1970-90. The OECD (1998) STAN database has an employment series back to 1970 for Japan and the USA under ISIC rev 3, but there are a number of industries for which data are unavailable for both countries. ${ }^{3}$ Consequently the study commences with the 1980 IO tables for Japan and the USA. While Australia generated IO tables for 1977-78, no complementary employment data are available. Consequently the 1989 and 1996-97 Australian IO tables were utilised. 
The 1997 IO tables for Japan and the USA are based on ISIC rev3, while the Australian table for (1996-97) is based on the ANZSIC classification obtained from Australian Bureau of Statistics, ABS, 2001). Current price IO tables are utilised, because the IO tables for all countries are not available at constant prices for 1980, 1990 and 1997. As noted, even with constant price IO tables, comparisons are limited by the need to take account of exchange rates.

While structural change in the three countries has involved both the shift to service based activities and the emergence of new industries, which is reflected in the use of ISIC rev3, rather than ISIC rev2, it is decided to facilitate comparisons by collapsing both classifications to a common 17 sector classification, which is shown in the Appendix. The STAN database is also classified under ISIC rev3, so that the employment data can be readily reconciled with the IO tables for Japan and the USA. Quarterly ABS employment data by industry are available under the ANZSIC classification from 1984. This can be readily collapsed into the common 17 sector classification. West's GRIMP software package (West, 1993) is used to undertake the IO calculations.

\section{EMPIRICAL RESULTS}

Table 1 shows the computed Type I employment multipliers for Australia, Japan and the US in 1980, 1990 and 1997. For example in 1997 each additional job created in the Australian Food, Beverages and Tobacco industry would create 3.75 extra jobs in the economy. To provide a clearer picture, the 17 industries are classified into the 6 top employment generating industries, 5 medium employment generating industries and 6 low employment generating industries. The results are presented in Table 2.

Table 1. Sectoral employment type I multipliers for Australia, Japan and the USA

\begin{tabular}{|c|c|c|c|c|c|c|c|c|c|}
\hline \multirow{2}{*}{$\begin{array}{l}\text { New } \\
\text { Code }\end{array}$} & \multirow{2}{*}{ Sector } & \multicolumn{2}{|c|}{ Australia } & \multicolumn{3}{|c|}{ Japan } & \multicolumn{3}{|c|}{$\overline{U S A}$} \\
\hline & & 1989 & 1997 & 1980 & 1990 & 1997 & 1982 & 1990 & 1997 \\
\hline 1 & Agriculture, forestry \& fishing & 1.43 & 1.50 & 1.86 & 1.73 & 1.63 & 2.66 & 2.36 & 2.12 \\
\hline 2 & Mining \& quarrying & 2.26 & 3.06 & 2.45 & 1.59 & 1.69 & 1.99 & 2.29 & 2.48 \\
\hline 3 & Food, beverages \& tobacco & 3.46 & 3.75 & 2.80 & 2.53 & 2.08 & 3.84 & 3.74 & 3.72 \\
\hline 4 & TCF \& leather & 1.65 & 1.66 & 1.98 & 1.81 & 1.61 & 2.05 & 1.88 & 1.94 \\
\hline 5 & Wood \& paper products, furniture & 2.53 & 2.23 & 2.41 & 2.17 & 1.84 & 2.12 & 2.19 & 1.94 \\
\hline 6 & $\begin{array}{l}\text { Chemicals, petroleum, coal, rubber \& } \\
\text { non-metallic minerals }\end{array}$ & 2.56 & 2.46 & 3.36 & 3.13 & 2.36 & 3.04 & 2.82 & 2.77 \\
\hline 7 & Basic Metals/Fabricated Products & 2.37 & 2.31 & 3.53 & 2.77 & 2.32 & 2.31 & 2.29 & 2.26 \\
\hline 8 & Machinery \& equipment & 1.85 & 1.89 & 2.41 & 2.67 & 2.27 & 2.20 & 2.19 & 2.39 \\
\hline 9 & Other Manufacturing nec & 1.13 & 1.53 & 1.29 & 1.29 & 1.34 & 1.46 & 1.39 & 1.75 \\
\hline 10 & Electricity, gas \& water & 2.02 & 2.30 & 2.79 & 2.37 & 2.16 & 3.62 & 2.53 & 2.64 \\
\hline 11 & Construction & 1.69 & 1.57 & 1.92 & 1.87 & 1.54 & 2.38 & 2.04 & 1.94 \\
\hline 12 & Wholesale retail, restaurants etc & 1.28 & 1.42 & 1.42 & 1.37 & 1.34 & 1.26 & 1.26 & 1.29 \\
\hline 13 & Transport \& storage & 1.57 & 1.85 & 1.59 & 1.70 & 1.34 & 1.84 & 1.67 & 1.70 \\
\hline 14 & Communication services & 1.41 & 1.69 & 1.33 & 1.39 & 1.53 & 1.24 & 1.21 & 1.75 \\
\hline 15 & Finance \& insurance & 1.48 & 1.54 & 1.34 & 1.41 & 1.32 & 1.72 & 1.72 & 1.83 \\
\hline 16 & Property \& bus services & 1.54 & 1.80 & 1.67 & 1.80 & 1.76 & 1.52 & 1.53 & 1.48 \\
\hline 17 & Community, Social \& Personal Services & 1.19 & 1.23 & 1.51 & 1.22 & 1.21 & 1.16 & 1.19 & 1.16 \\
\hline
\end{tabular}

Source: OECD IO tables for all countries, except Australia (ABS, 2001) and OECD DSTI (STAN industrial database) 2001 (annual) for the USA and Japan. AUSSTATS quarterly employment data by ANZSIC (annual average) for Australia. 
Table 2. Top, medium and low employment generating industries: Australia, Japan and USA

\begin{tabular}{l|c|c|c|c}
\hline Industry & Australia & Japan & US & $\begin{array}{c}\text { Common } \\
\text { Industries }\end{array}$ \\
\hline & \multicolumn{4}{|c}{1980} \\
\hline Top 6 & NA & $7,6,3,10,2 \& 8$ & $3,10,6,1,11 \& 7$ & $3,6,7,10$ \\
Medium 5 & NA & $5,4,11,1 \& 16$ & $8,5,4,2 \& 13$ & $4 \& 5$ \\
Low 6 & NA & $13,17,12,15,14 \& 9$ & $15,16,9,12,14 \& 17$ & $9,12,14,15 \& 17$ \\
\hline & \multicolumn{4}{|c}{1990} \\
\hline Top 6 & $3,6,5,7,2 \& 10$ & $6,7,8,3,10 \& 5$ & $3,6,10,1,2 \& 7$ & $3,6,7,10$ \\
Medium 5 & $8,11,4,13,16$ & $11,4,16,1 \& 13$ & $8,5,11,4 \& 15$ & $11 \& 13$ \\
Low 6 & $15,1,14,12,17 \& 9$ & $2,15,14,12,9 \& 17$ & $13,16,9,12,14 \& 17$ & $9,12,14,17$ \\
\hline & \multicolumn{4}{|c}{1997} \\
\hline Top 6 & $3,2,6,7,10 \& 5$ & $6,7,8,10,3 \& 5$ & $3,6,10,2,8 \& 7$ & $3,6,7 \& 10$ \\
Medium 5 & $8,13,16,14 \& 4$ & $16,2,1,4 \& 11$ & $1,11,4,5 \& 15$ & 4 \\
Low 6 & $11,15,9,1,12 \& 17$ & $14,12,13,9,15 \& 17$ & $14,9,13,16,12 \& 17$ & $9,12 \& 17$ \\
\hline
\end{tabular}

Source: Table 1.

As can be seen from this Table 2, four of the consistently high employment generating industries in these countries are Food, Beverage and Tobacco (3); Chemicals, Petroleum, Coal, Rubber \& Non-Metallic Minerals (6); Basic Metals/Fabricated Products (7); and Electricity, Gas and Water (10), with the first three industries being part of manufacturing. It is interesting to note that the high employment generating industries in 1980 and/or 1990 are almost the same as those in 1997. Thus, given the broad definition of industries, there is no evidence that high employment generating industries have changed since 1980. Likewise the low employment generating industries have not changed markedly since 1980 across the three countries. ${ }^{4}$ Except for Other Manufacturing (9), the remainder are service sector industries. However, due to the lack of disaggregated employment data for all the three countries, this analysis does not show changes in new low or new high employment sub-sectors which may have been created or disappeared within a particular sector through time.

From the results in Tables 1 and 2, it seems that the magnitude and sectoral ranking of employment multiplier ratios have not undergone a major change since 1980 at an aggregate level. A correlation coefficient of 0.87 between the US and Australian $T^{E}$ statistics across industries for 1997 and a correlation coefficient of 0.73 between the US and Japan clearly indicates that the high and low employment generating industries are very similar across countries. Therefore, one can conclude that not only the high and low employment generating industries have not changed through time, but also, on a relative basis, these industries are very similar across these three countries (See also the last column of Table 2).

Table 3 indicates that on average the $T^{E}$ in the USA is greater than those of Japan and Australia, increasing slightly from 2.02 in 1990 to 2.07 in 1997. The Australian employment multiplier ratio is not only higher than Japan's, but also unlike Japan it has exhibited an upward trend since 1990. One possible explanation is that Japanese industry has been characterised by overmanning which is being addressed as 
the country slips deeper into recession. See Bon and Yashiro (1996) for a detailed discussion of the IO analysis of demand-side and supply-side of the Japanese economy.

Table 3. Average employment multiplier ratios for Australia, Japan and the USA

\begin{tabular}{lccc}
\hline \multicolumn{1}{c}{ Country } & 1980 & 1990 & 1997 \\
\hline Australia & NA & 1.9 & 2.0 \\
Japan & 2.1 & 1.9 & 1.7 \\
USA & 2.1 & 2.0 & 2.1 \\
\hline
\end{tabular}

Source: See Table 1.

IO multiplier analysis has several limitations and the results must be interpreted carefully. For example, multiplier effects tend to ignore or mask displacement effects because many resources could already be fully utilised in the economy. Thus, positive multiplier effects may include hidden opportunity costs and substitution effects. See Valadkhani (2003) for a discussion of IO restrictive assumption in a similar context. Although these restrictive assumptions embedded in an IO system make generalisations difficult, the findings are, to some extent, indicative of the forces at work.

\section{SUMMARY}

This paper examines high employment industries across three OECD economies (namely Australia, Japan and the U.S), drawing on the intersectoral relationships that are revealed by IO analysis. Despite some major difficulties with obtaining consistent data, some interesting results have been obtained. It is found that not only the high and low employment generating industries have not changes through time, but also, on a relative basis, these industries are very similar across these three countries. It appears that three out of the four highest employment generating industries belong to manufacturing. 
Appendix. Concordance for ISIC rev 2 and 3, ANZSIC and 17 sector classification

\begin{tabular}{|c|c|c|c|c|c|c|}
\hline ISIC 2 & OECD IO, 1970-90 & ISIC 3 & $\begin{array}{c}\text { STAN Database \& IO } 1997 \text { (Japan } \\
\text { \& USA) }\end{array}$ & & ANZSIC & $\begin{array}{l}\text { New } \\
\text { Code } \\
\end{array}$ \\
\hline 1 & Agr, forestry \& fishing & 01-05 & Agr, forestry \& fishing & $011-42$ & Agr, forestry \& fishing & 1 \\
\hline 2 & Mining \& quarrying & $10-14$ & Mining \& quarrying & $110-52$ & Mining & 2 \\
\hline 3 & Food, beverages \& tobacco & $15-16$ & Food, Beverages \& Tobacco & 21 & Food, bev \& tobacco & 3 \\
\hline 4 & Textiles, apparel \& leather & $17-19$ & Textiles, Leather \& Footwear & 22 & TCF\& leather & 4 \\
\hline 5 & Wood products \& furniture & 20 & Wood \& Wood Products \& Cork & 23 & Wood \& paper product & 5 \\
\hline 6 & Paper, paper products etc & $21-22$ & Pulp, Paper, Printing etc & 24 & Print, pub \& recorded media & 5 \\
\hline 7 & Industrial chemicals & $23-25$ & Chemical, Rubber, Plastics etc & 25 & Petrol, coal, chem\& related & 6 \\
\hline 8 & Drugs \& medicines & 26 & $\begin{array}{l}\text { Other Non-Metallic Mineral } \\
\text { Products }\end{array}$ & 26 & Non-metal mineral product & 6 \\
\hline 9 & Petroleum \& coal products & & & & & 6 \\
\hline 10 & Rubber \& plastic products & & & & & 6 \\
\hline 11 & Non-metallic min products & & & & & 6 \\
\hline 12 & Iron \& steel & $27-28$ & Basic Metals/Fabricated Products & 27 & Metal product & 7 \\
\hline 13 & Non-ferrous metals & & & & & 7 \\
\hline 14 & Metal products & & & & & 7 \\
\hline 15 & Non-electrical machinery & $29-33$ & Machinery \& Equipment & 28 & Machinery \& equipment & 8 \\
\hline 16 & Office/comp machinery & $34-35$ & Transport Equipment & & & 8 \\
\hline 17 & Electrical apparatus, nec & & & & & 8 \\
\hline 18 & $\begin{array}{l}\text { Radio, TV \& } \\
\text { communication }\end{array}$ & & & & & 8 \\
\hline 19 & Shipbuilding \& repairing & & & & & 8 \\
\hline 20 & Other transport & & & & & 8 \\
\hline 21 & Motor vehicles & & & & & 8 \\
\hline 22 & Aircraft & & & & & 8 \\
\hline 23 & Professional goods & & & & & 8 \\
\hline 24 & Other manufacturing & $36-37$ & Manufacturing Nec; Recycling & 29 & Other & 9 \\
\hline 25 & Electricity, gas \& water & $40-41$ & Electricity, gas \& water supply & $361-70$ & Electricity, gas \& water & 10 \\
\hline 26 & Construction & 45 & Construction & $411-25$ & Construction & 11 \\
\hline 27 & Wholesale \& retail trade & $50-55$ & Wholesale, retail: Restaurants etc & $451-79$ & Wholesale trade & 12 \\
\hline 28 & Restaurants \& hotels & & & $511-32$ & Retail trade & 12 \\
\hline & & & & $571-74$ & Accomm, cafes etc & 12 \\
\hline 29 & Transport \& storage & $60-63$ & Transport \& storage & $611-70$ & Transport \& storage & 13 \\
\hline 30 & Communication & 64 & Post and telecommunications & $711-12$ & Communication services & 14 \\
\hline 31 & Finance \& insurance & $65-67$ & Financial Intermediation & $731-52$ & Finance \& insurance & 15 \\
\hline 32 & Real estate \& bus. services & $70-74$ & Real Estate, Renting \& Business & $771-86$ & Property \& bus services & 16 \\
\hline 33 & CSP services & $75-99$ & CSP Services & $811-20$ & Gov admin \& defence & 17 \\
\hline 34 & Government services & & & $841-44$ & Education & 17 \\
\hline 35 & Other producers & & & $861-72$ & Health \& comm services & 17 \\
\hline \multirow[t]{2}{*}{36} & Statistical discrepancy & & & $911-33$ & Cultural \& rec services & 17 \\
\hline & & & & $951-70$ & Personal \& other services & 17 \\
\hline
\end{tabular}

Source: See Table 1.

Note: This table shows the concordance for ISIC rev2 and ISIC rev3. The concordance is approximate because there are differences between ISIC rev2 and rev3 that appear at the four digit level and hence are not apparent at the two digit level. 


\section{REFERENCES}

Australian Bureau of Statistics (ABS) (2001) Australian National Accounts: InputOutput Tables, Cat. 5209, Canberra.

Bon, R. and Yashiro, T. (1996) Comparative stability analysis of demand-side and supply-side input-output models: the case of Japan, 1960-90, Applied Economics Letters, 3, 349-54.

Conway, R S. (1977) The stability of regional input-output multipliers, Environment \& Planning A, 9, 197-214.

Diamond, J. (1975) Inter-industry indicators of employment potential, Applied Economics, 7, 265-73.

Mattas, K., and Shrestha, C.M. (1991) A new approach to determining sectoral priorities in an economy: input-output elasticities, Applied Economics, 23, 247-54.

Mitchell, W.F. and Mosler, W. B. (2002) Fiscal policy and the job guarantee, Australian Journal of Labour Economics, 5, 243-59.

OECD (1998) STAN Industrial Database, OECD, Paris.

Valadkhani, A. (2003) Using input-output analysis to identify Australia's high employment generating industries, Australian Bulletin of Labour, 29, 199-217.

West, G.R. (1993), Input-Output Analysis for Practitioners: An Interactive Input-Output Software Package User's Guide Version 7.1 (GRIMP), Department of Economics, The University of Queensland, Brisbane.

\footnotetext{
${ }^{1}$ If one country was being analysed and the IO tables for the different years were all expressed in constant prices, the employment multiplier formula would be appropriate.

${ }^{2}$ It is acknowledged that these calculations, while unit free, do not provide guidance about the so called bang for a buck since the nominal value of the extra output generated by one additional employee in industry $\mathrm{j}$ will reflect the productivity of labour, other input costs and the profit margin.

${ }^{3}$ An hours based measure of employment would have been preferred, or at least one that differentiated between part-time and full-time employment, but such data are not available for Japan.

${ }^{4}$ Conway (1977) notes that there are a number of possible causes of changes in the multipliers over time namely: technological change; increasing (or decreasing) benefits from scale of production ("scale economies"); changes in product composition (within industrial sectors) including entirely new products (or loss of products); closure (opening) of entire branches of industries; changes in relative prices; and input substitution as a result of response to price changes or technological change.
} 